\title{
Mentoring in emergency medicine: the art and the evidence
}

\author{
MarianneYeung, MD, FCFP; Janet Nuth, MD; Ian G. Stiell, MD, MSc
}

\section{ABSTRACT}

A mentor is a person who takes a special interest in the professional development of a junior colleague and provides guidance and support. Mentoring can be beneficial for students, residents, junior colleagues and researchers and can be very rewarding for the physician who provides this guidance. Although mentoring is a well-recognized topic in academic medicine, relatively little has been written about mentoring in emergency medicine (EM). Consequently, we conducted a literature review on mentoring in EM and present our findings in this paper. We discuss different models of mentoring, factors that foster the development of strong mentorship programs, the responsibilities of mentors and mentees, and issues specific to mentorship of female, minority and research physicians. We also present several case scenarios as a basis for recommendations for teachers and learners in EM.

Keywords: mentors, emergency medicine, literature review, education, research, medical student, resident faculty, female, minority

\section{RÉSUMÉ}

Un mentor est une personne qui prend un intérêt particulier dans le développement d'un collègue moins expérimenté et lui fournit des conseils et du soutien. Le mentorat peut être bénéfique pour les étudiants et les résidents ainsi que des collègues et des chercheurs en début de carrière. II peut aussi s'avérer très gratifiant pour le médecin mentor qui fournit cette orientation. Bien que le mentorat soit un sujet bien connu dans le milieu de la médecine universitaire, il existe relativement peu d'articles sur le mentorat en médecine d'urgence. Par conséquent, nous avons effectué une revue de la littérature sur ce sujet et présentons nos conclusions dans cet article. Nous discutons de divers modèles de mentorat, des facteurs qui favorisent le développement de programmes de mentorat solides, des responsabilités du mentor et du mentoré, et d'enjeux propres au mentorat de femmes, de minorités et de médecins chercheurs. Nous présentons aussi plusieurs mises en situation servant de base aux recommandations à l'intention des enseignants et des apprenants en médecine d'urgence.

\section{CASE SCENARIOS}

Case scenario 1 - medical student: After working together for a few shifts, a medical student asks a staff physician to be her mentor, as she is interested in pursuing a career in emergency medicine (EM). The physician accepts, but is unsure how to proceed.

Case scenario 2 - emergency resident: A senior EM resident reveals to a staff physician that he is feeling stressed, unhappy and despondent. He has previously considered suicide but is not presently suicidal. What steps should the staff physician take following this disclosure?

Case scenario 3 - colleague: A new faculty member, fresh from residency, asks a midcareer emergency physician for advice on integrating work and personal life. What counsel should be given to this new colleague?

Case scenario 4 - research: A senior resident approaches his EM research director expressing a desire to follow a career path in research. How should the research director proceed from here?

\section{INTRODUCTION}

A mentor is a person who takes a special interest in the professional development of a junior colleague and provides guidance and support. The mentor may have a number of roles within this professional relationship including advisor, supporter, tutor, employer, sponsor and role model. ${ }^{1,2}$ The key ingredient to a successful mentoring relationship is a genuine commitment from both the mentor and the mentee., ${ }^{1,3}$ Mentoring has been identified as an essential component to career development for academics in general and for medicine in

From the Department of Emergency Medicine, University of Ottawa, Ottawa, Ont.

Submitted May 7, 2009; Revised Sep. 4, 2009; Accepted Sep. 9, 2009

This article has been peer reviewed.

CJEM 2010;12(2):143-9 
particular. ${ }^{46}$ Although mentorship may be perceived as a burden, potential benefits for the mentor include an opportunity to share one's knowledge and experience, satisfaction and pride in a mentee's success, a chance to give back to the profession, the gain of a new collaborator, recognition from peers and credit for academic promotion. ${ }^{4,5,7,8}$

Teachers and learners in EM recognize the importance of mentorship, but relatively little has been written about mentoring in our specialty. Our objectives for this paper were 2-fold. First, we wished to conduct a review of the literature on mentoring in EM. Second, based on this review as well as on our own experiences, we wished to synthesize recommendations for successful mentoring of students, residents, colleagues and researchers within EM.

\section{METHODS}

We conducted a literature review to identify articles pertaining to mentoring specific to EM. We performed 2 independent searches using PubMed (www.pubmed.gov/) and Cochrane Central Register of Controlled Trials databases. Keywords "mentor" and "emergency medicine" were interpreted by the search engine as medical subject headings "Mentors" AND "Emergency Medicine." A search for these medical subject headings as major topics identified 13 manuscripts for potential inclusion. We reviewed reference lists of included articles and identified 3 additional manuscripts.

Abstracts were reviewed for relevance to mentoring in EM; discrepancies between reviewers were resolved by discussion. Thirteen full-text articles were retrieved for assessment. We then conducted a qualitative review of these 13 articles, which constitutes the basis for discussion and recommendations presented in this paper. Because of the scarcity of EM-specific papers in the medical literature, we have included in this discussion a number of general medical mentoring papers found to be useful.

\section{RESULTS}

We retrieved 13 citations from the literature search and reviewed the full-text articles. Eleven articles were from the United States and 2 were from the United Kingdom (Table 1). ${ }^{6,8-19}$ There were 6 commentaries on mentoring in general, ${ }^{6,9-13} 2$ commentaries on mentorship of EM clinician-educators ${ }^{8,14}$ and 1 commentary on mentorship of female academicians. ${ }^{15}$ Three articles described surveys of trainees, ${ }^{16,17,20}$ and 1 article described a distance EM mentorship program. ${ }^{18}$

\section{DISCUSSION}

\section{Importance of mentoring}

Ninety to ninety-five percent of medical trainees consistently rate mentoring as important, or express a wish to develop a mentoring relationship. ${ }^{21-24} \mathrm{~A}$ majority of surveyed residency program directors also believe that mentorship is important to a resident's career and professional development. ${ }^{25}$ Program directors who had experienced mentorship in their own careers were more likely to endorse an active mentorship program for residents. ${ }^{26}$ Mentored residents are nearly twice as likely to describe excellent career preparation as their nonmentored peers. ${ }^{24}$ In addition, mentorship influences selection of medical specialty, and is a particularly strong factor for physicians who choose an academic career path. ${ }^{4}$

Mentoring of medical faculty can have a positive impact. Mentored medical faculty score significantly higher on career satisfaction scales. ${ }^{27}$ Mentored faculty are 2.3 times as likely to achieve academic promotion as compared with those without mentors. ${ }^{28}$ With respect to retention, junior faculty without mentors are more than twice as likely to leave their organization as compared with mentored faculty. ${ }^{29}$

Although mentoring is generally felt to be important, many medical trainees and junior faculty have not identified a mentor. A recent systematic review of 15 studies found mentoring prevalence rates of $19 \%$ to $93 \%$; less than $40 \%$ of medical students had a mentor. ${ }^{4}$ An

Table 1. Summary of relevant mentorship articles in the emergency medicine literature

\begin{tabular}{lccc}
\hline Study & Country & Year & Type of article \\
\hline Garmel $^{6}$ & USA & 2004 & Commentary \\
Coates et al. $^{8}$ & USA & 2003 & Clinician-educator \\
Jouriles et al. $^{9}$ & USA & 1997 & Commentary \\
Binder and DeBehnke $^{10}$ & USA & 1998 & Commentary \\
Marco and Perina $^{11}$ & USA & 2004 & Commentary \\
Rosen et al. $^{12}$ & USA & 2008 & Commentary \\
Wright and Hedges $^{13}$ & USA & 2009 & Faculty handbook \\
Farrell et al. $^{14}$ & USA & 2004 & Clinician-educator \\
Lewis $^{15}$ & USA & 2003 & Gender issues \\
Blumstein and Cone $^{16}$ & USA & 1998 & Survey \\
Okereke and Naim $^{17}$ & UK & 2001 & Survey \\
Coates et al. $^{18}$ & USA & 2004 & Program description \\
Okereke $^{19}$ & UK & 2000 & Survey \\
\hline
\end{tabular}


overwhelming $98 \%$ of academic physicians identify the lack of mentorship as being the first or second most important factor hindering their career progress. ${ }^{30}$

\section{Models of mentoring}

Mentoring can take different forms. Most familiar is individual mentoring, where a protege pairs with one mentor. In a study of internal medicine residencies with formal mentoring programs, $90 \%$ chose this individual style of mentoring. Program directors assigned mentors in $50 \%$ of programs; others encouraged mentor choice by the resident, or selection with dual input from the program director and trainee. ${ }^{25}$ Of course, there are individual mentoring relationships that develop spontaneously outside of official residency programs.

Group mentoring is also popular, and involves one mentor meeting simultaneously with many mentees. As mentees may be at different levels of training, the most junior learners also benefit from interaction with their peers.

Box 1. Responsibilities within a mentoring relationship

Mentor responsibilities

- Treat the mentee with courtesy and respect

- Be sensitive to cultural, gender, religious and ethnic differences

- Limit the number of mentees for whom they assume responsibility

- $\quad$ Promote the interests of the mentee rather than those of the mentor

- Be sensitive to behavioural or physical changes that may indicate mentee stress

- $\quad$ Facilitate networking (e.g., meetings, conferences, social events)

- Offer career advice and write candid letters of recommendation

Mentee responsibilities

- Conduct self in a mature and ethical manner

- Be mindful of mentor time constraints

- Take initiative in asking questions

- Take responsibility for directing own career

Additional research mentor responsibilities

- Impart knowledge about research ethics and the responsible conduct of research (e.g., honesty, accuracy, efficiency, productivity)

- $\quad$ Promote scientific integrity and lead by example

- $\quad$ Steer the mentee toward the location of research guidelines

- Provide thoughtful oversight of mentee's research

- Hold regular meetings with mentees (e.g., once per month)

Adapted from Birdi and Goldstein, ${ }^{1}$ Steneck, ${ }^{2}$ Ramani et al., ${ }^{5}$ Marks and Goldstein, and Ramanan et al. ${ }^{33}$
The newest model takes place by email, and is known as telementoring or distance mentorship. This is particularly helpful to allow continuation of an established mentoring relationship, as in the case where one of the mentor pair moves to a new centre. Challenges of distance mentorship centre around the use of technology and having adequate time for mentor pair communication. ${ }^{31}$ Mentors describe long-distance mentoring as less demanding but also potentially less personally fulfilling than on-site mentoring. ${ }^{32}$

\section{Recommendations for effective mentoring}

The role of the mentor is to guide the protege and serve as a resource, facilitator and networker (Box 1). 1,2,5,7,33 Good mentors are willing to share their own failures as well as their successes and to provide open, honest feedback to the mentee. It is a myth that the mentor should be the single person with all the answers. In fact, a mentee may need several mentors, each pertaining to a different career aspect. ${ }^{1,12}$ Mentees also have responsibilities, as listed in Box 1.

There are mentoring issues specific to medical research (Box 1). Mentored junior faculty rate their research preparation and research skills more highly than do faculty without mentors. ${ }^{2,27}$ Mentees are likely to devote more time to research, are more productive in terms of research grants and publications, and are more likely to complete a thesis. ${ }^{4}$ Lack of mentorship has been identified as a specific obstacle to completing scholarly work and publication among physicians in diverse medical specialties.

Recommendations for getting started in a mentoring relationship are listed in Box 2. Suggestions for discussion topics related to training, personal life, professional career and future meetings are given in Box 3 .

Characteristics of a good mentor have been well

\section{Box 2. Getting started in mentoring}

- $\quad$ Set aside 30 minutes for the first meeting

- $\quad$ Get acquainted (e.g., backgrounds, interests, hobbies)

- Exchange phone numbers and email addresses

- Discuss best modes of communication and times to be reached

- Request a copy of the mentee's curriculum vitae

- Define expectations of both mentee and mentor

- Identify the mentee's short- and long-term goals

- $\quad$ Identify 3 areas to work on together

- $\quad$ Schedule regular meetings (e.g., every 1-2 months)

Adapted from Birdi and Goldstein, ${ }^{1}$ and Wright and Hedges. 
described. In a resident study, good mentors were seen as active listeners, with the ability to clearly identify the protege's strengths and assist in defining and attaining goals. ${ }^{34}$ Among mentored faculty, prized mentors are perceived as being knowledgeable and respected in their field, are able to provide both professional and personal support and place high value on the mentoring relationship. ${ }^{29}$ Both resident and faculty groups have observed that effective mentoring requires a certain personal compatibility between the 2 parties. ${ }^{34}$ It is important for mentors and mentees to be aware of the potential pitfalls (Box 4).

Women and members of minority groups may find it more difficult to identify potential mentors, and it is important to recognize that a mentor does not need to be of the same gender or minority group as the mentee. ${ }^{4,27}$ Mentoring relationships must be established early on for these physician groups; studies indicate that they have been less likely to achieve major leadership

Box 3. Recommended discussion topics for mentoring meetings

Training issues

- Program choices and applications (e.g. CaRMS, CCFP[EM], FRCP[EM])

- Mentee's progress within his or her program or career path

- Issues arising from program and rotation evaluations

- Elective selection

- $\quad$ Preparation of presentations and papers (e.g., grand rounds, research manuscripts)

Personal and professional issues

- $\quad$ Clinical, research and ethical issues

- Integration of work and personal life

- Time management

- Conflict resolution

- Professionalism

- Financial matters (e.g., practice management, disability \& life insurance, loans, taxes, retirement planning)

- Monitor for signs of professional or personal distress

- In case of difficulty, the mentor may act as a confidant, advocate and safety net

- $\quad$ The mentor may need to refer the mentee to other professionals (e.g., experts in physician wellness)

Future issues

- $\quad$ Setting goals - the mentee can be encouraged to write out short- and long-term career goals; progress toward these goals can be reviewed on a regular basis

- $\quad$ Career counseling and planning - encourage mentees to view job prospects realistically

- Networking, making new contacts and meeting new mentors

CaRMS = Canadian Residency Matching Service.

Adapted from Birdi and Goldstein, ${ }^{1}$ Steneck, ${ }^{2}$ Garmel, ${ }^{6}$ and Wright and Hedges. ${ }^{13}$ positions or senior academic ranks, even after adjusting for such potential confounders as measures of academic productivity and years of service. ${ }^{35-38}$ Faculty report being relatively isolated and disadvantaged by subtle discrimination; they are not included in the formal and informal mentoring opportunities that are available to their peers. Distance mentoring programs have been effectively used to target underrepresented minority faculty. ${ }^{39,40}$ Many studies of women in medicine identify lack of mentorship as a major obstacle to career advancement. ${ }^{20,41}$ In a survey of medical students, residents and junior faculty at the University of California, 24\% of women identified the lack of mentorship as one of the most negative experiences of their career. ${ }^{42}$ Mentors of women are advised to consider that many women excel in collaborative academic ventures, rather than traditional individualistic settings. ${ }^{43}$

Faculty development programs have been shown to improve mentoring skills. ${ }^{44}$ The most effective mentoring workshops included practical exercises, such as demonstrations, role plays and review of videotaped scenarios. Simulated mentoring encounters, followed by discussion and feedback have been found to be valuable learning tools for mentors. ${ }^{44,45}$

Leaders are advised to overtly value and reward mentoring rather than allowing it to remain an invisible and only implicitly valuable component of their educational programs. ${ }^{5}$ Strong mentoring programs are encouraged by linking mentorship to academic promotion, and by providing mentors with faculty development and protected time. ${ }^{5,27}$ Previous work shows that funded mentors have more mentees than do those without funding. ${ }^{32}$ Universities may provide funding for mentoring; in our department, mentors receive academic credit points.

Formal evaluation of the effectiveness and efficiency of specific aspects of mentorship is lacking in the medical literature. There are no validated evaluation tools,

\section{Box 4. Potential problems in a mentoring relationship}

- Lack of time and commitment from either mentee or mentor

- Overdependence of the mentee on the mentor

- Making a "clone"

- $\quad$ Following a mentor's agenda (e.g., using the mentee as "free labour")

- Lack of respect for the boundaries of the relationship

- Divulging confidences

- Not knowing limitations - the mentor must know their limits and refer the protege for expert help as appropriate

Adapted from Rose et al., ${ }^{3}$ Garmel, ${ }^{6}$ Wright and Hedges, ${ }^{13}$ and Williams et al. ${ }^{34}$ 
and existing instruments do a poor job of evaluating mentoring programs, perhaps in part because of the imprecise nature of mentoring itself. ${ }^{46}$ Two recent reviews suggest that the majority of mentoring programs lack concrete structure or evaluation; however, surveyed participants indicated high levels of satisfaction and interest in the programs.,47

\section{Mentoring in EM}

Students considering our specialty may not only lack emergency physician advisors but also receive negative advice from non-EM physicians. ${ }^{16}$ Emergency medicine faculty who act as general advisors to medical students have an opportunity to serve as role models, disseminate accurate information about our specialty and refute negative advice from other faculty. ${ }^{10,18}$ Distance mentoring via email is especially useful for students at schools without affiliated EM residency programs. ${ }^{18}$ One small survey demonstrated that EM residents are accepting of either midcareer or senior doctors as mentors. ${ }^{19}$ Mentorship has been identified as a means to develop professionalism and effective research skills in EM trainees. ${ }^{48,49}$

Emergency physicians may need to seek advisors in other departments or institutions. ${ }^{11,50}$ Emergency medicine clinician-educators in particular have fewer mentor choices than do researchers, and are often best served by a network of mentors rather than a single advisor. ${ }^{14}$

All mentoring models are represented in Canadian EM. At our university, each EM resident selects an individual mentor with the advice of their program director. University of Ottawa medical students participate in group mentoring. Each group consists of 10 students spanning all 4 years of medical school and 1 faculty member. Our department has offered an informal form of group mentoring for women for over a decade. Female emergency physicians meet quarterly to discuss career- and gender-specific issues; residents and junior faculty gain an opportunity to network with role models and mentors.

Research mentoring is well established at the University of Ottawa. Here, a junior faculty member completes a master of science in epidemiology while being intensively mentored by a senior clinical researcher and epidemiologist. The junior researcher is guided in project management, grant writing and manuscript preparation. This 2-year fellowship may be followed by a 3 -year period whereby the new investigator has protected time to develop a research program under the mentorship of a senior investigator.
The Society for Academic Medicine's Virtual Advisor Program and the Ontario Medical Association Mentoring Program ${ }^{51}$ are examples of distance mentoring, whereby medical students considering a career in EM are matched with faculty. ${ }^{18}$ Mentors are available to discuss issues by email, including rotation recommendations, clerkships, residency applications and specialized interests within EM, such as pediatrics, medical education and critical care. ${ }^{6,18}$

\section{RESOLUTION OF CASE SCENARIOS}

Case scenario 1 - medical student: After working together for a few shifts, a medical student asks a staff physician to be her mentor, as she is interested in pursing a career in EM. The physician accepts, but is unsure how to proceed.

Time should be set aside for the first mentoring meeting. There, the mentor and mentee will discuss their expectations, the short- and long-term goals of the mentoring relationship and plan for regularly scheduled meetings.

Case scenario 2 - emergency resident: A senior EM resident reveals to a staff physician that he is feeling stressed, unhappy and despondent. He has previously considered suicide but is not presently suicidal. What steps should the staff physician take following this disclosure?

The staff physician should express concern and offer a safe, supportive environment to the resident. Realizing that this issue is beyond the expertise of an emergency physician, the resident should be referred to wellness programs offered by the university and the Physician Health Network through the Canadian Medical Association. The faculty member should assist the resident in arranging an appointment with a psychiatrist and offer to accompany him to the appointment. The staff physician should also seek the resident's permission to share this disclosure with the EM residency program director, to permit their involvement and close supervision.

Case scenario 3 - colleague: A new faculty member, fresh from residency, asks a midcareer emergency physician for advice on integrating work and personal life. What counsel should be given to this new colleague?

The mentor should share her own successes and failures with the mentee and facilitate networking. The protege should be assisted to identify her professional and personal priorities, and thereby to develop her own career and life path. Regular, perhaps annual, meetings will allow the mentee to review and self-audit her performance in her roles both inside and outside of medicine. 
Case scenario 4 - research: A senior resident approaches his EM research director and expresses a desire to follow a career path in research. How should the research director proceed?

The research director should discuss the commitment required for a career in EM research and offer to assist this young doctor should he wish to pursue this route. One model of preparation could include a research fellowship followed by a period of protected time as a new investigator.

\section{CONCLUSION}

Mentorship is an important determinant of professional success. Emergency physicians have many opportunities to become involved in this activity, which holds rewards for both mentor and protege. Review of the medical literature reveals few manuscripts specific to mentoring in EM. Keys to success include commitment to the mentoring relationship, an awareness of each party's responsibilities and avoidance of potential pitfalls. Individual, group and distance mentoring formats have all been found to be valuable. Adaptations of the mentoring process are recommended for female physicians, members of minority groups, researchers and educators. In this article, we have provided an overview of the key components of mentoring in EM. Future research could address the more formal evaluation of mentoring initiatives.

Competing interests: None declared.

\section{REFERENCES}

1. Birdi N, Goldstein R. Handbook on faculty mentoring. Ottawa (ON): Faculty of Medicine, University of Ottawa; 1999.

2. Steneck NH. Introduction to the responsible conduct of research. Rockville (MD): Office of Research Integrity; 2004.

3. Rose GL, Rukstalis MR, Schuckit MA. Informal mentoring between faculty and medical students. Acad Med 2005;80: 344-8.

4. Sambunjak D, Straus SE, Marusle A. Mentoring in academic medicine — a systematic review. JAMA 2006;296:1103-15.

5. Ramani S, Gruppen L, Krajic Kachur E. Twelve tips for developing effective mentors. Med Teach 2006;28:404-8.

6. Garmel GM. Mentoring medical students in academic emergency medicine. Acad Emerg Med 2004;11:1351-7.

7. Marks MB, Goldstein R. The mentoring triad: mentee, mentor, and environment. J Rheumatol 2005;32:216-8.

8. Coates WC, Hobgood CD, Birnbaum A, et al. Faculty development: academic opportunities for emergency medicine faculty on education career tracks. Acad Emerg Med 2003;10:1113-7.
9. Jouriles NJ, Kuhn GJ, Moorhead JC, et al. Faculty development in emergency medicine. Acad Emerg Med 1997;4:1078-86.

10. Binder LS, DeBehnke DJ. The importance of being earnest — and student-centered. Acad Emerg Med 1998;5:1-3.

11. Marco CA, Perina DG. Mentoring in emergency medicine: challenges and future directions. Acad Emerg Med 2004;11: 1329-30.

12. Rosen P, Edlich RF, Rosen CL, et al. Becoming a specialist in emergency medicine. 7 Emerg Med 2008;34:471-6.

13. Wright DW, Hedges JR. Mentoring faculty members to the next level. SAEM Faculty Development Handbook. Des Plaines (IL): Society for Academic Emergency Medicine; 2009.

14. Farrell SE, Digioia NM, Broderick KB, et al. Mentoring for clinician-educators. Acad Emerg Med 2004;11:1346-50.

15. Lewis RJ. Some thoughts regarding gender issues in the mentoring of future academicians. Acad Emerg Med 2003;10: 59-61.

16. Blumstein HA, Cone DC. Medical student career advice related to emergency medicine. Acad Emerg Med 1998;5:69-72.

17. Okereke CD, Naim M. Mentoring senior house officers. Is there a role for middle grade doctors? Emerg Med J 2001;18: 259-62.

18. Coates WC, Ankel F, Birnbaum A, et al. The virtual advisor program: linking students to mentors via the world wide web. Acad Emerg Med 2004;11:253-5.

19. Okereke CD. Mentoring — the trainee's perspective. I Accid Emerg Med 2000;17:133-5.

20. Reisman AB, Gross C. Gender differences in the ability to identify a mentor at morning report: a multi-institutional survey. Teach Learn Med 2002;14:236-9.

21. Aagaard EM, Hauer KE. A cross-sectional descriptive study of mentoring relationships formed by medical students. 7 Gen Intern Med 2003;18:298-302.

22. Levy BD, Katz JT, Wolf MA, et al. An initiative in mentoring to promote residents' and faculty members' careers. Acad Med 2004;79:845-50.

23. Ricer RE, Fox BC, Miller KE. Mentoring for medical students interested in family practice. Fam Med 1995;27:360-5.

24. Ramanan RA, Taylor WC, Davis RB, et al. Mentoring matters - mentoring and career preparation in internal medicine residency training. 7 Gen Intern Med 2006;21:340-5.

25. Castiglioni A, Bellini LM, Shea JA. Program directors' views of the importance and prevalence of mentoring in internal medicine residencies. 7 Gen Intern Med 2004;19:779-82.

26. Donovan A, Donovan J. Mentorship in postgraduate training programmes: views of Canadian programme directors. Med Educ 2009;43:155-8.

27. Palepu A, Friedman RH, Barnett RC, et al. Junior faculty members' mentoring relationships and their professional development in U.S. medical schools. Acad Med 1998;73:318-23.

28. Wise MR, Shapiro H, Bodley J, et al. Factors affecting academic promotion in obstetrics and gynaecology in Canada. J Obstet Gynaecol Can 2004;26:127-36.

29. Benson CA, Morahan PS, Sachdeva AK, et al. Effective faculty preceptoring and mentoring during reorganization of an 
academic medical center. Med Teach 2002;24:550-7.

30. Jackson VA, Palepu A, Szalacha L, et al. "Having the right chemistry": a qualitative study of mentoring in academic medicine. Acad Med 2003;78:328-34.

31. Miller LC, Devaney SW, Kelly GL, et al. E-mentoring in public health nursing practice. J Contin Educ Nurs 2008;39: 394-9.

32. Luckhaupt SE, Chin MH, Mangione CM, et al. Mentorship in academic general internal medicine. 7 Gen Intern Med 2005;20:1014-8.

33. Ramanan RA, Phillips RS, Davis RB, et al. Mentoring in medicine: keys to satisfaction. Am J Med 2002;112:336-41.

34. Williams LL, Levine JB, Malhotra S, et al. The good-enough mentoring relationship. Acad Psychiatry 2004;28:111-5.

35. Cone DC, Richardson LD, Todd KH, et al. Health care disparities in emergency medicine. Acad Emerg Med 2003;10: 1176-83.

36. Cydulka RK, D'Onofrio G, Schneider S, et al. Women in academic emergency medicine. Acad Emerg Med 2000;7:9991007.

37. Tesch BJ, Wood HM, Helwig AL, et al. Promotion of women physicians in academic medicine. Glass ceiling or sticky floor? JAMA 1995;273:1022-5.

38. Palepu A, Carr PL, Friedman RH, et al. Minority faculty and academic rank in medicine. JAMA 1998;280:767-71.

39. Lewellen-Williams C, Johnson VA, Deloney LA, et al. The POD: a new model for mentoring underrepresented minority faculty. Acad Med 2006;81:275-9.

40. Yager J, Waitzkin H, Parker T, et al. Educating, training, and mentoring minority faculty and other trainees in mental health services research. Acad Psychiatry 2007;31:146-51.

41. Mark S, Link H, Morahan P, et al. Innovative mentoring programs to promote gender equity in academic medicine. Acad Med 2001;76:39-41.
42. Osborn EH, Ernster VL, Martin JB. Women's attitudes toward careers in academic medicine at the University of California, San Francisco. Acad Med 1992;67:59-62.

43. Lewis RJ. Some thoughts regarding gender issues in the mentoring of future academicians. Acad Emerg Med 2003; $10: 59-60$

44. Connor MP, Bynoe AG, Redfern N, et al. Developing senior doctors as mentors: a form of continuing professional development: report of an initiative to develop a network of senior doctors as mentors: 1994-1999. Med Educ 2000;34:747-53.

45. Sloan REG, McMillan J. Developing mentoring skills for general practitioners using a simulated doctor. Med Educ 2003;37:1044-5.

46. Berk RA, Berg J, Mortimer R, et al. Measuring the effectiveness of faculty mentoring relationships. Acad Med 2005; 80:66-71.

47. Buddeberg-Fischer B, Herta K-D. Formal mentoring programmes for medical students and doctors - a review of the Medline literature. Med Teach 2006;28:248-57.

48. Larkin GL, Binder L, Houry D, et al. Defining and evaluating professionalism: a core competency for graduate emergency medicine education. Acad Emerg Med 2002;9:1249-56.

49. Blanda M, Gerson LW, Dunn K. Emergency medicine resident research requirements and director characteristics. Acad Emerg Med 1999;6:286-91.

50. Biros MH, Barsan WG, Lewis RJ, et al. Supporting emergency medicine research: developing the infrastructure. Acad Emerg Med 1998;5:177-84.

51. Ontario Medical Association Mentoring Program. Available www.oma.org/student/mentorship.asp (accessed 2010 Jan 18).

Correspondence to: Dr. Ian Stiell, Clinical Epidemiology Unit, Office F657, Ottawa Hospital Research Institute, The Ottawa Hospital, Civic Campus, 1053 Carling Ave., Ottawa ON K1Y 4E9; istiell@ohri.ca

\section{LOOKING FOR A NEW JOB?}

In print and online, the best way to advertise or find employment opportunities in academic, administrative or community emergency medicine is through the Canadian Journal of Emergency Medicine.

Print version of CJEM: The deadline for advertising in the print version of CJEM is one month before issue date. For ad rates and further information, please contact Beverley Kirkpatrick or Deborah Rodd at CMA Publications (800 663-7336 or 613 731-8610 x2127/2314, advertising@cma.ca).

\section{Looking for an Emerg Doc?}

\author{
SPECIAL BONUS: As a bonus to print advertisers, \\ CJEM is pleased to offer website advertising \\ space on CAEP's website (www.caep.ca) free of \\ charge.
}

CAEP website alone: Advertising in the CAEP website alone is billed at a rate of $\$ 100$ a month, and can be obtained at any time. Please contact CAEP's Head Office for advertising solely on the website (800 463-1158 or advertising@caep.ca). 